\title{
DEVELOPMENT OF TECHNICAL SOLUTIONS FOR PREVENTING DISCHARGE OF LIQUID TECHNOGENIC WASTE AT ENTERPRISES USING SURVIVAL PROCESSING PROCESSES
}

\author{
Artem V. KOLESNIKOV, Tatiana V. DAVYDKOVA \\ D. Mendeleev University of Chemical Technology of Russia, Moscow, Russia, artkoles@list.ru
}

https://doi.org/10.37904/metal.2020.3589

\begin{abstract}
In the course of the work, a resource-saving version of the work of all basic elements was developed. The developed technological scheme will allow wastewater to be treated to modern maximum permissible concentrations (MPC) standards due to the highly efficient removal of heavy and non-ferrous metals and organic impurities, which can significantly reduce the cost of water supply to the enterprise.
\end{abstract}

Keywords: Maximum permissible concentrations, wastewater, chemical plants

\section{INTRODUCTION}

As part of the implementation of the Federal Target Program "Research and Development in Priority Directions for the Development of the Scientific and Technological Complex of Russia for 2014-2020" implemented by the Ministry of Science and Higher Education, new technical solutions have been developed aimed at preventing the discharge of liquid industrial waste at enterprises using galvanochemical processing processes surface.

The rational and efficient use of water resources is a complex task, the solution of which is carried out by engineering, technical and scientific workers of various specialties and industries. The relevance of its solution is aimed at the sustainable development of the economy, increasing the level of defense of the country and improving the quality of life.

Despite significant differences in the processing technology of metal products and composite materials, all of them create waste during operation, which can be in a liquid, solid or gaseous state, representing a different degree of danger and toxicity to the environment and humans. It is known that $85-90 \%$ of liquid industrial waste contains $95 \%$ of hazardous components [1,2].

Liquid industrial wastes from industrial enterprises are represented by wastewater and spent technological solutions [3]. In technological processes, wastewater is polluted with various organic and inorganic substances $[4,5]$.

Depending on the operations used, these can be solvents, dyes, surfactants and detergents, oils, lubricants, compositions. The most common minerals are acids, alkalis, salts: sulphates, chlorides, nitrites, phosphates, carbonates; heavy and non-ferrous metal ions: $\mathrm{Cu}, \mathrm{Sn}, \mathrm{Pb}, \mathrm{Bi}, \mathrm{Cr}, \mathrm{Ni}, \mathrm{Cd}$; To obtain coatings of the required quality, complexing agents based on ammonia, tartaric, acetic and other organic acids, as well as other complex compounds, are widely used. Recently, the number of technological stages where organic components are used, both individually and as part of mixtures or compositions, has been significantly increasing [6-8].

Pollutants exceeding permissible limits pose a danger to both the environment and human health, being toxic and poisonous $[3,4]$. 


\section{CHEMICAL INDUSTRY ANALYSIS}

Analysis of the surfaces of industrial enterprises using galvanochemical processes for surface treatment of metals and plastics showed the following typical problems:

- The existing scheme of wastewater treatment and equipment used does not always provide wastewater treatment from a number of components to existing modern normal maximum permissible concentrations (MPC).

- As a rule, there are no systems for automatic regulation and control of purification parameters (medium acidity, redox potential, chemical oxygen consumption).

- The necessary reduction in the concentration of ions of heavy and non-ferrous metals is not always ensured, since the water being purified has different $\mathrm{pH}$ values.

- $\quad$ There are no effective systems for wastewater treatment from organic pollution.

- $\quad$ The precipitate is not regularly removed due to residual metals (metal hydroxides), which leads to a decrease in its efficiency due to leaching of the precipitate and "slip" including components.

- $\quad$ There are no systems for the disposal of waste technological solutions and electrolytes.

In the course of the project implementation in Russia, the applied organic additives were classified according to the effect of the process of extracting the dispersed metal phase from aqueous solutions, which can be conditionally divided into 6 groups:

Group 1

- $\quad$ Ligands for complexation with metal ions ( $\mathrm{Cu}, \mathrm{Ni}, \mathrm{Zn}, \mathrm{Cd})$.

- $\quad$ Tartrate, EDTA, pyrophosphate.

- Sulfonates, ethanolamine, diethanolamine, triethanolamine, organic acids, etc.

Group 2

- $\quad$ Surfactants for degreasing, pickling, during surface treatment.

- Non-ionic surfactants: OP-7, OP-10, Syntanol, NaDDS, NaDBS.

Group 3

- $\quad$ Corrosion inhibitors during surface treatment. $\mathrm{Cu}, \mathrm{Al}$, steel.

- Benzotriazole, cationic surfactants.

Group 4

- Washes to remove polymer compositions, varnishes, stains.

- Solvents: alcohols, acetone, dimethylformamide, diethanolamine.

Group 5

- $\quad$ Etching solutions (Cu, Sn, Sn-Pb, Al).

- Acids: inorganic, organic.

- Organic ligands.

- Corrosion inhibitors.

Group 6

- $\quad$ Additives for leveling during the deposition of metals ( $\mathrm{Cu}, \mathrm{Ni}, \mathrm{Zn})$.

- Alcohols, surfactants, aldehydes, ketones.

As experience shows, modern high-tech science-intensive production includes not only galvanic shops, but also mechanical and assembly shops, assembly materials and assembly products from them, lines and 
workshops for the production of printed circuit boards of electronic equipment. where paint coatings are applied, which are often used for cleaning together, as shown schematically in Figure 1.

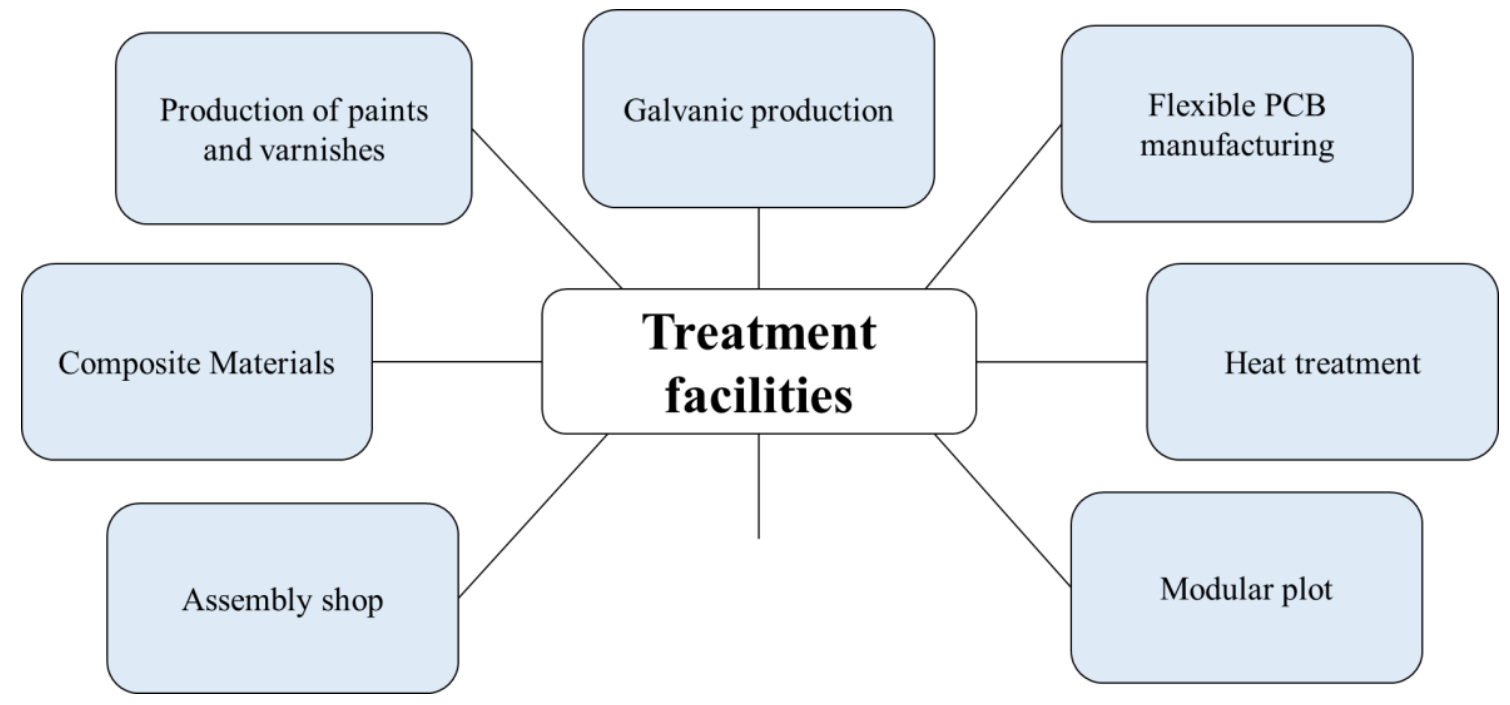

Figure 1 Sources of wastewater

\section{CHEMICAL WASTEWATER TREATMENT OFFERS}

At the same time, the constantly tightening legal requirements for the discharge of wastewater into a centralized sewage system contribute to the creation of drainless water supply systems for industrial enterprises. To solve this problem, we propose a combined scheme for the utilization of liquid industrial waste, consisting of a treatment unit to MPC (preliminary treatment) and a closed water circulation unit (desalination and disposal of concentrates). The circuit diagram is presented in Figure 2.

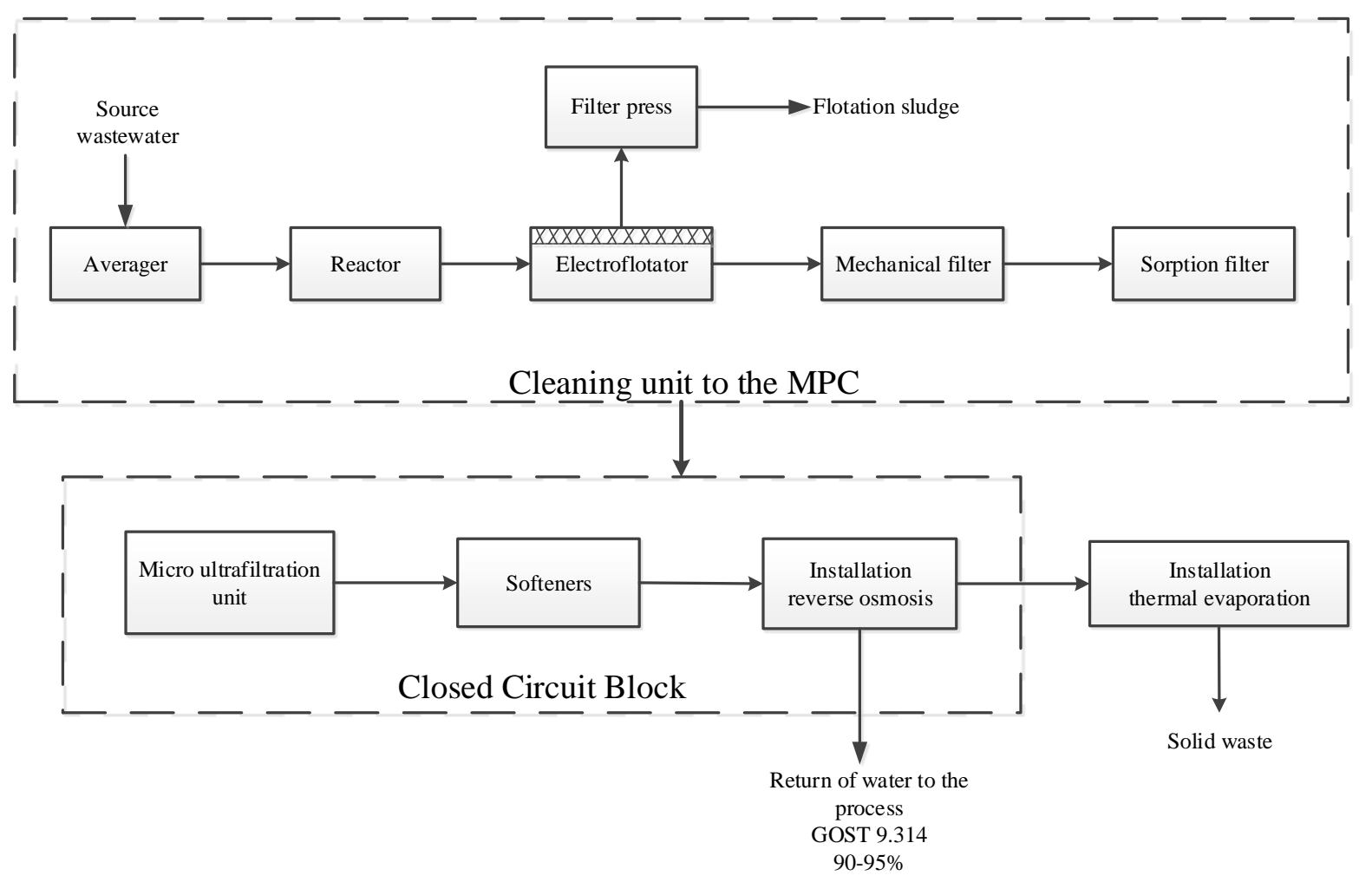

Figure 2 Proposed combined liquid industrial (technogenic) waste disposal scheme 
The composition of the purification unit before MPC (pre-treatment) includes: averager, reactor, electroflotator, a complex of bulk mechanical filters, a complex of sorption filters, a filter press for sludge dewatering.

The composition of the closed water circulation unit (desalination and disposal of concentrates) includes: ultrafiltration unit, reverse osmosis unit, module for thermal evaporation of electrolyte. An experimental sample is located at one of the engineering enterprises in the city of Moscow.

\section{CONCLUSION}

When implementing the above approach, the discharge of mineralized wastewater is eliminated, and up to $95 \%$ of wastewater treated to the level of GOST 9.314 (1 cat.) It is returned to the process, which can significantly reduce the cost of water supply to the enterprise. In the course of the work, a resource-saving version of the work of all basic elements was developed.

The developed technological scheme will make it possible to treat waste water to modern MPC standards due to the highly efficient removal of heavy and non-ferrous metals and organic impurities.

\section{ACKNOWLEDGEMENTS}

The work was carried out with financial support DI. Mendeleev (project No. Z-2020-004)

\section{REFERENCES}

[1] VINOGRADOV, S.S. Environmentally friendly galvanic production. Moscow: Globus. 2002.

[2] KOLESNIKOV, V.A., IL'IN, V.I, BRODSKIJ, V.A., KOLESNIKOV, A.V. Electroflotation in the processes of water purification and extraction of valuable components from liquid industrial waste. Overview. Theoretical foundations of chemical technology. 2017. vol. 4, no. 51, pp.361-375.

[3] VU, T.P., VOGEL, A., KERN, F., PLATZ, S., MENZEL, U., GADOW, R. Characteristics of an electrocoagulationelectroflotation process in separating powdered activated carbon from urban wastewater effluent. Separation and Purification Technology. 2014. vol. 134. pp. 196.

[4] YANG, H.G., CHUN, H.Y., PAK, D. Improvement of sludge anaerobic degradability by combined electro-flotation and electro-oxidation treatment. Biochemical Engineering J. 2014, vol. 90, pp. 44.

[5] CERQUEIRA, A.A., SOUZA, P.S.A., MARQUES, M.R.C. Effects of direct and alternating current on the treatment of oily water in an electro-flocculation process. Braz. J. Chem. Eng. 2014, vol. 31, no. 3. pp. 693. 